Clinical Image

Meghan K. Arndts*, DO

\title{
Retained colon in the subcutaneous fat after colostomy reversal
}

https://doi.org/10.7556/jaoa.2020.153

Received April 22, 2020; accepted June 4, 2020;

published online October 26, 2020

A 58-year-old woman presented to a general surgery center in 2019 with a painful lump and intermittent drainage. She had undergone a Hartmann procedure in 2008 for diverticulitis, followed by sigmoid colectomy with reversal of colostomy 6 months later. In 2011, she developed a painful lump near her old colostomy site. She noted that the lump waxed and waned in size; it would periodically become red and drain fluid. In 2015, she underwent exploratory laparotomy with closure of an enterocutaneous fistula, but this did not resolve her

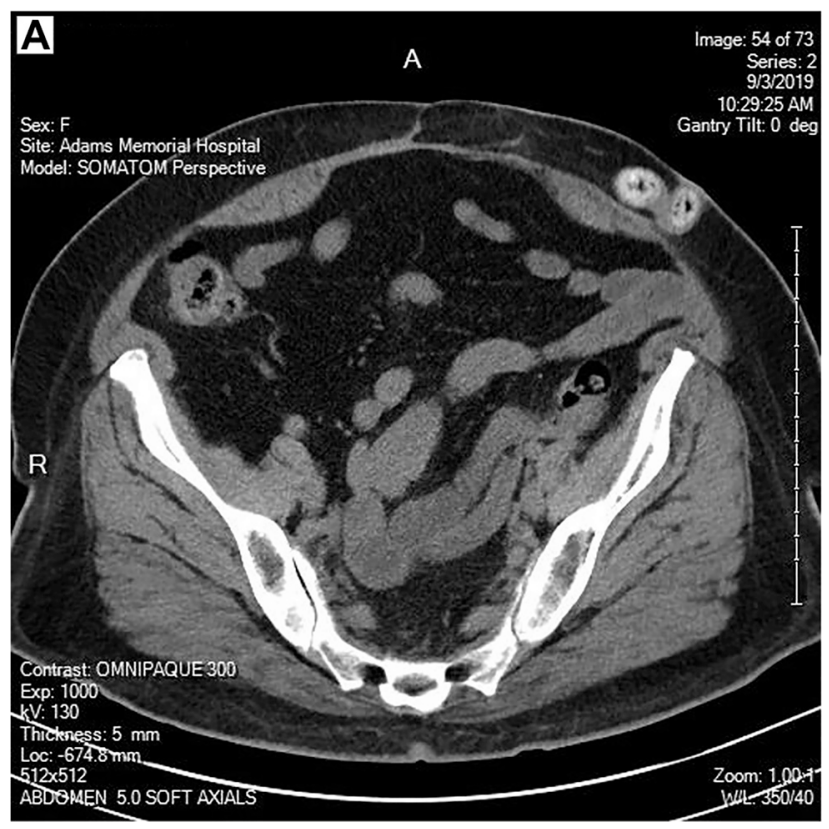

*Corresponding author: Meghan K. Arndts, DO, Adams Health Network, 1617 Woodedge Ave Springfield, Ohio 45504-1363, USA, E-mail: arndtsmk@aol.com

Ә Open Access. @ 2021 Meghan K. Arndts, published by De Gruyter. ((c)) BY International License. symptoms. After she presented to our office with continued pain and intermittent drainage from the lump, a CT scan was performed, which demonstrated bowel in the subcutaneous fat, no hernia, and no connection to intra-abdominal bowel (image A). The patient underwent surgical excision, and intraoperative findings and pathology were consistent with retained colon containing inspissated stool (image B). The patient's symptoms resolved after this procedure.

This case illustrates the importance of obtaining a thorough history and performing a complete physical examination, ${ }^{1}$ supplemented by the patient's prior health records. In the era of electronic medical records and telehealth, the importance of history and physical examination are often overlooked. ${ }^{2-4}$ This patient had seen several surgeons and her primary care physician on multiple occasions, receiving various diagnoses from sebaceous cyst to hernia. After a thorough history, physical examination, and review of old CT scans, the patient was able to receive an accurate diagnosis prior to surgery

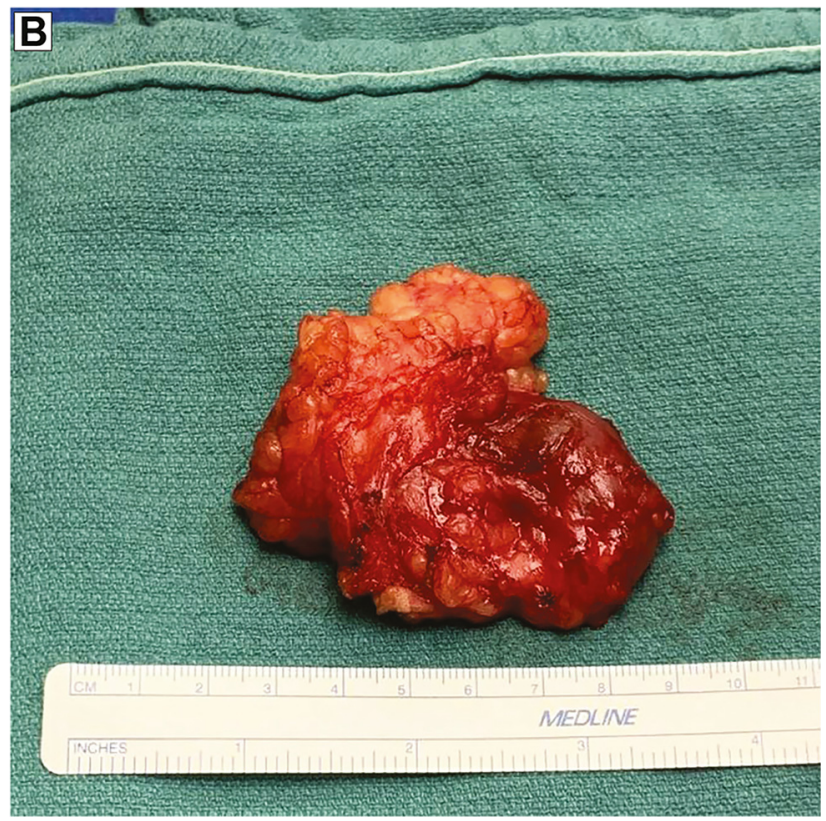

This work is licensed under the Creative Commons Attribution 4.0 
and an issue that had been troubling her for 11 years was resolved.

\section{References}

1. Centor RM, Geha R, Manesh R. The pursuit of diagnostic excellence. JAMA Netw Open. 2019;2(12):e1918040. doi:10.1001/ jamanetworkopen.2019.18040.
2. Asif T, Mohiuddin A, Hasan B, Pauly RR. Importance of thorough physical examination: a lost art. Cureus. 2017;9(5):e1212. doi:10. 7759/cureus.1212.

3. Carr S. Reexamining the physical exam. Improve Dx Newsletter. 2020;7(1):1-5. Available at https://www.improvediagnosis.org/ wp-content/uploads/2020/01/Vol.-7-Issue-1.pdf. Accessed September 30, 2020.

4. Zaman J, Verghese, A, Elder, A. The value of physical examination: A new conceptual framework. Southern Med J. 2016;109(12):754-757. doi:10.14423/SMJ.0000000000000573. 